\title{
Impact of the COVID pandemic on survivors of childhood cancer and survivorship care: lessons for the future
}

\author{
Maya Prasad $^{1,2}$ - Savita Goswami ${ }^{2,3} \cdot$ Jayita Deodhar ${ }^{2,3} \cdot$ Girish Chinnaswamy $^{1,2}$
}

Received: 2 September 2021 / Accepted: 30 December 2021 / Published online: 5 January 2022

( $)$ The Author(s), under exclusive licence to Springer-Verlag GmbH Germany, part of Springer Nature 2022

\begin{abstract}
Purpose The COVID pandemic has greatly impacted cancer care, with survivorship care being accorded low priority. We aimed to assess the impact of the COVID pandemic on survivorship services at our centre, as well as on survivors of childhood cancer (CCS).

Methods We analyzed the trends in survivorship care at our centre from March 2020 to June 2021 compared to previous years. We also conducted an online survey of adolescent and young adult (AYA-CCS) following up at the After Completion of Treatment Clinic, Mumbai, to assess the impact of the COVID pandemic and ensuing restrictions on our cohort of survivors. Sibling responses were used as comparator (CTRI/2020/11/029029).

Results There was a decrease in in-person follow-ups and increase in remote follow-ups over the first few months of the pandemic. While in-person visits steadily increased after October 2020 and reached pre-pandemic numbers, distant followups continue to be higher than pre-pandemic. Evaluable responses from the survey of 88 AYA-CCS and 25 siblings revealed new-onset health concerns in $29.5 \%$ of AYA-CCS, missed follow-up visit in 52\% and varying degrees of mental health issues in $12.5 \%$. While most survivors were able to cope with the stresses of the pandemic, $20 \%$ of siblings reported being unable to cope.

Conclusions Survivorship services continue to be affected well into the pandemic, with increased use of distant follow-ups. While AYA-CCS experienced significant physical, mental health issues and psychosocial concerns as a result of the COVID pandemic, they coped better than siblings during this stressful time, possibly due to multiple, holistic support systems including family, peer support groups and healthcare team.
\end{abstract}

Keywords Childhood cancer survivors $\cdot$ COVID $\cdot$ Adolescent and young adult

Abbreviations

AYA Adolescent and young adult

CCS Childhood cancer survivors

Maya Prasad

maya.prasad@gmail.com

1 Division of Paediatric Oncology, Tata Memorial Centre, Parel, Mumbai, India 400012

2 Homi Bhabha National Institute (HBNI), Anushakti Nagar, Mumbai, India

3 Department of Psycho-Oncology, Tata Memorial Centre, Parel, Mumbai, India 400012

\section{Introduction}

For over a year now, the unprecedented global COVID-19 pandemic has affected people and societies at multiple, wide-ranging levels. The impact of the pandemic on patients with cancer and survivors has been extensively reported [1]. Studies have reported adverse influences on mortality and morbidity, including psychosocial distress and mental health [1-5]. Delays and disruptions in cancer care services due to the pandemic have been near-universal [6-10]. Due to the need to allocate resources to patients on active treatment and reduce overcrowding and transmission of infection, survivorship care has been modified at most centres [11]. There is increasing use of tele-health, postponement or cancellation of face-to-face appointments and non-urgent tests [11]. Adolescent and young adult (AYA) survivors of childhood cancer (CCS) are known to grapple with medical and psychological issues even under normal circumstances [12-14]. 
Surveys of childhood adolescent and young adult (CAYA) survivors revealed a high rate of disruption in cancer care as well as increased psychological distress, uncertainty regarding the future and the need for information concerning their past cancer and treatment in relation to COVID $[15,16]$.

The After Completion of Treatment (ACT) Clinic at Tata Memorial Hospital (TMH), Mumbai, is one of the largest late effects services in India, catering to over 3000 long-term survivors of childhood cancer from all parts of India [17, 18]. A strict nation-wide lockdown was announced on 24th March 2020 and continued until 31st May 2020, when it was lifted in stages. Varying degrees of restrictions continued until November 2020. While phased vaccinations started in January 2021, India faced a devastating second wave in the first few months of 2021.

All through the pandemic, survivors with concerns were permitted to visit our centre for follow-up; however, logistical issues due such as discontinuation/restriction of travel services and fear of infection during hospital visits severely limited follow-up. Several local healthcare providers also restricted their routine services in order to accommodate the rising cases of COVID infection. During the initial few months of telephonic and virtual follow-ups, we noted a high level of mental and physical distress amongst our survivors. Many of our survivors reported having had health problems (either new or pre-existing) and being unable to get appropriate care from local doctors or being unable to travel to our centre. Based on the feedback received from these conversations, we conducted an online survey of survivors and their siblings, designed to understand the spectrum of physical, mental health and psychosocial issues faced, as well as access to care during this unprecedented pandemic.

In this manuscript, we report our experiences with survivorship care during the past 18 months of the pandemic and the impact of the pandemic on our survivors during the early phase of the pandemic.

\section{Methods}

Modifications in survivorship care and trends in follow-up In mid-March 2020, based on hospital policy, we initiated telephonic contact to postpone all follow-up appointments [19]. From April to June 2020, our late effects Clinic contacted all survivors with appointments scheduled during this period via telephone, WhatsApp calls and emails and conducted brief consultations. Our clinic is predominantly serviceoriented and coordinates the medical and psychosocial care of a majority of our survivors - hence, survivors with concerns received more detailed and focused (often multiple) consultations. Survivors requiring active medical intervention continued to be seen in regular outpatient clinics, with COVID precautions, and if logistically possible. Those who were on long-term medication but could not visit our centre were sent prescriptions by WhatsApp or email, and in some cases, medication was couriered to the survivors. The medical care of such survivors was conducted either distantly by our specialty clinics or coordinated with local physicians. After the lifting of pandemic restrictions in end-2020, we resumed routine services at our Clinic and continued remote follow-up via telephone, video calls and email. Even after lifting of restrictions, survivors at low risk of late effects were actively encouraged to continue distant follow-up and shared care, in view of frequent travel restrictions and surges in COVID infections. All throughout this period, our psychologist and counselling services as well as the pre-existing WhatsApp peer support group remained active.

All interactions were documented in our database and electronic medical records. For the purpose of this manuscript, we analyzed the trends in survivorship care at our centre during the period March 15, 2020, to June 30, 2021. The number of teleconsultations as a proportion of total followup visits was compared to the corresponding 3-month period in 2019 using the Fisher's exact $t$-test. The 3-monthly numbers of in-person visits and teleconsultations (telephonic/ video consultations and email consultations) were compared by phases of lockdown and other restrictions.

Online survey of survivors and siblings Based on feedback from the early teleconsultations, we conducted an online survey to document the various health problems faced by AYA CCS during the COVID pandemic, to assess the impact of the COVID pandemic on physical and mental health and social/personal lives of the survivors, and to identify areas for specific health and psychosocial intervention and to assess the access to healthcare during this period. Questions pertained to the period from March 2020 to September 2020 loosely referred to as 'the past 6 months'. Adolescent and young adult (15-39 years) survivors of childhood cancer registered in After Completion of Treatment Clinic were eligible to participate in this survey. They were required to be familiar with English to be able to understand and respond to the survey, and to provide informed consent. Siblings closest in age to the survivors and preferably of the same gender were also invited to participate. They were required to be aware of the past history of survivor and current health and psychosocial issues, be familiar with English and to provide informed consent. Siblings with a history of cancer diagnosis or treatment were ineligible. We anticipated a convenient sample size of 75 survivors and 25 siblings.

Two versions of the structured online survey (one each for survivors and siblings) were designed using Google Forms by the investigators: paediatric oncologist (MP) and psycho-oncologists (SG, JD). All investigators were actively 
involved in the care of cancer survivors during this period and are familiar with the health and psychosocial issues faced by adult survivors of childhood cancer in our population. The language used was simple, conversational English to make it easier for non-native speakers to understand and respond to this form. There was a short consent on the first page of the survey, and the reply 'yes' was mandatory to proceed with survey. The survivor survey questionnaire had 37 questions (mainly single-choice or multiple-choice), and was divided into the following sections: Baseline details, General health, Recent health problems, COVID-related questions, Family and social life and Satisfaction survey. The sibling questionnaire also had 37 questions and was similar to those in the Survivor questionnaire for comparison (Supplementary Figs. 1 and 2). While most questions were binary questions with yes-no responses, many questions had ordinal options for responses (e.g. very dissatisfied, dissatisfied, neither satisfied nor dissatisfied, satisfied, very satisfied). All eligible survivors with valid email addresses in the database of the late effects Clinic were invited via email to answer the questionnaire meant for survivors and to forward the link to their eligible siblings. We also posted the link on a pre-existing WhatsApp peer support group. The online survey was activated on November 1, 2020, for a period of 45 days after approval from the Institutional Ethics Committee ethics approval at Tata Memorial Hospital, and registration on the website of Clinical Trials registry of India (CTRI/2020/11/029029). Statistical analysis: In survey respondents, information regarding demographics, original cancer diagnoses and pre-existing chronic health conditions were extracted from our database. Due to the relatively small number of participants, the ordinal responses were grouped together (broadly positive responses vs neutral responses vs negative responses). Descriptive statistics are expressed using median and range, and categorical variables represented using frequencies and percentage. The survey responses of siblings were used as a comparator, and the $\chi^{2}$ test has been used for comparison of categorical items between survivors and sibling groups. Analysis was done using IBM® SPSS $® v$ 24.0.

\section{Results}

Trends in survivorship care As would be expected, there were almost no in-person follow-ups during the period April to June 2020, but numbers steadily increased after cessation of restrictions in October 2020 and returned to pre-pandemic levels by January 2021 (Fig. 1). Teleconsultations, which were highest during the lockdown period, continued to remain higher than the corresponding periods during the previous years, both as absolute numbers and as a proportion
Fig. 1 Trends in survivorship care

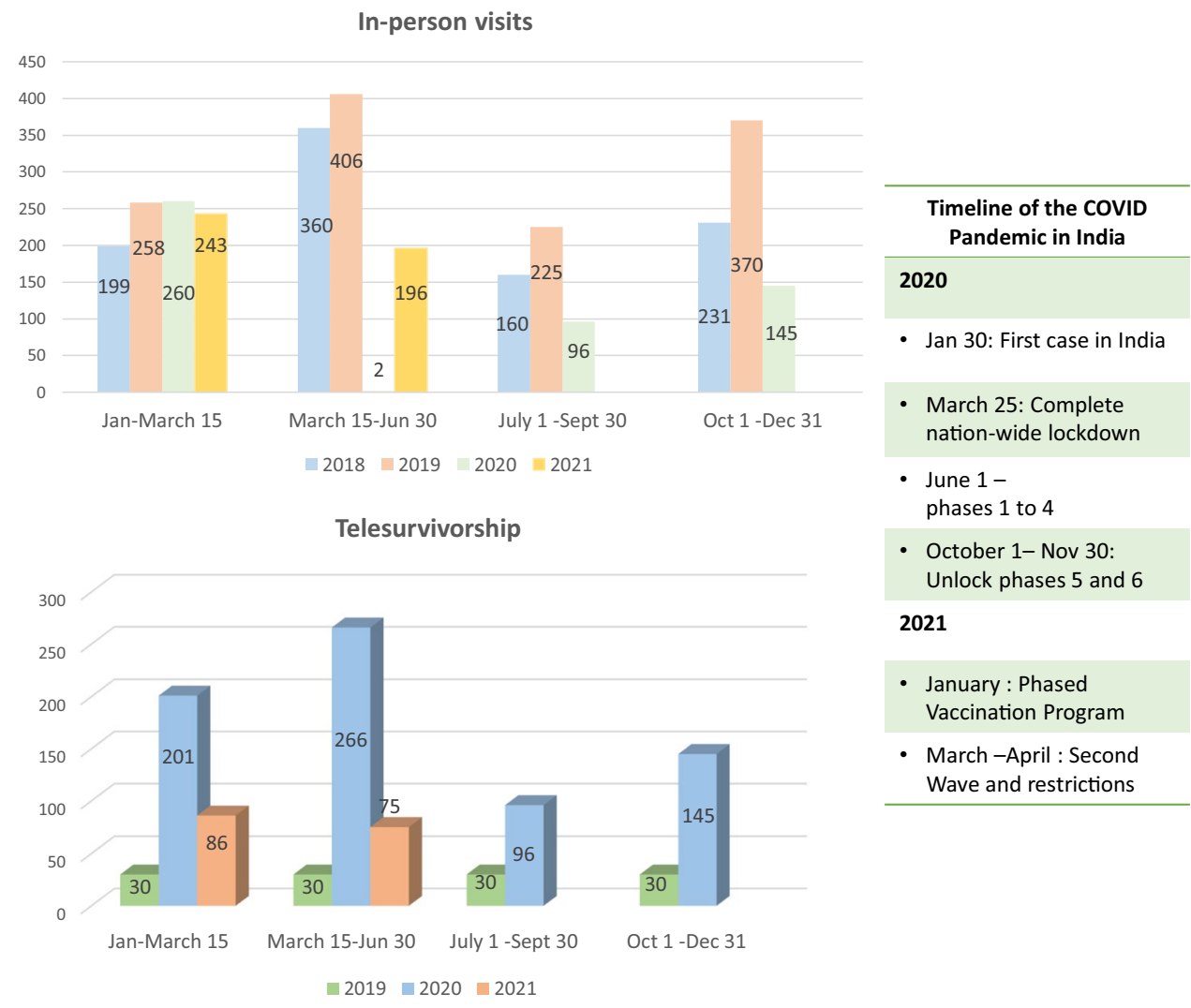


of total visits (Fig. 1). When analyzed by 3-month periods, teleconsultations as a proportion of total visits constituted 99\% (266/268) in March 15 to June 30, 2020, and 27\% (75/271) in March 15 to June 30, 2021, compared to 6.8\% (30/436) in March 15 to June 30, 2019, $p<0.0001$ for both comparisons. For the period Jan 1 to March 15, teleconsultations were 26\% (86/329) of total in 2021 and $46 \%$ (201/469) in 2020 compared to $10 \%(30 / 288)$ in $2019(p<0.0001)$; for the period July 1 to September 30, 50\% (96/192) in 2020 compared to $11.7 \%(30 / 255)$ in $2019(p<0.0001)$ and for the period October 1 to December 31, 50\% (145/290) in 2020 compared to $7.5 \%(30 / 400)$ in $2019(p<0.0001)$. While telephone $(59 \%)$ remains the most preferred mode of distant follow-up, WhatsApp and video calls (33\%) and email (8\%) are other effective modes.

Online survey of survivors and siblings The online survey was active from November 1 to December 15, 2020. There were a total of 133 responses - 101 from AYA CCS and 32 from siblings. Of these, 88 responses from survivors and 25 from siblings were evaluable. The non-evaluable responses included duplicate ( $n=10$ survivors, 5 siblings) or incomplete entries ( $n=1$ survivor), and those who were ineligible in view of age (age $<15$ years, $n=2$ survivors, 2 siblings). We contacted 220 survivors who in turn forwarded the link to their siblings; the response rates were $46 \%$ amongst CCS and $14 \%$ amongst siblings.

The demographic profile of the survey respondents and the medical information of CCS are listed in Table 1 and Supplementary Table 1. Survivors had been diagnosed with cancer at a median age of 10 years (range 1-18 years) and were a median of 14 years from diagnosis (range 5-34 years). Half of them (51\%) had a diagnosis of haematological neoplasms.
Physical and mental health concerns of survivors (Table 2) Over a fifth (21.6\%) of CCS self-reported a preexisting chronic illness, and $19 \%$ were on regular medication. Although over half (52.3\%) missed their follow-up visit, only one CCS missed their regular medication due to lack of access. Nearly a third (29.5\%) had new-onset health concerns that developed over the period March 15September 15, 2020, 13.6\% visited a doctor, $9 \%$ received some form of medication and one was hospitalized. Four survivors tested positive for COVID, and all had mild symptoms. Eleven (12.5\%) reported varying degrees of mental health issues. Overall, most CCS were satisfied with their health (69\%) and access to healthcare services (70\%) over this period. Over one-third (36\%) reported concern about contracting COVID infection, and how it would affect their health, being cancer survivors.

Physical and mental health concerns amongst siblings (Table 2) Nearly half of siblings (48\%) reported new health concerns; 2 had mental health issues (including clinical depression in one), with more siblings than CCS reported a new-onset health concern ( $n=12,48 \%$ vs $n=26,29.5 \%$, $p=0.09$ ), specifically transient physical ailments like fever, body ache and respiratory symptoms. More survivors, however, expressed dissatisfaction with personal health than siblings ( $n=11,12.5 \%$ vs none, $p=0.11$ ). New onset health concerns were more common in 'dissatisfied' survivors $(n=8,73 \%)$ than 'satisfied' $(n=11,18 \%, p<0.001)$ or 'neutral' survivors $(n=7,43 \%, p=0.2)$.

Psychosocial and family concerns (Table 3) Over one-third (34.6\%) of survivors reported that they felt neutral or dissatisfied with their living circumstances, $17 \%$ of employed CCS and $32 \%$ of family members lost their jobs and over half $(55.6 \%)$ reported financial distress during this period.
Table 1 Demographics of survey participants

\begin{tabular}{|c|c|c|c|}
\hline & Survivor $(n=88)$ & Sibling $(n=25)$ & $p$ \\
\hline Age in years (median, range) & $24(18-43)$ & $22(16-47)$ & 0.8 \\
\hline Gender (male:female) & $1.6: 1$ & $1.1: 1$ & 0.492 \\
\hline \multicolumn{4}{|l|}{ Current occupation } \\
\hline - Student & $45(51 \%)$ & $14(56 \%)$ & 0.8 \\
\hline - Employed & $41(46.6 \% ; 30$ part-time $)$ & $22(88 \% ; 12$ part-time $)$ & $<0.001$ \\
\hline - Completed studies, unemployed & $13(14.7 \%)$ & $1(4 \%)$ & 0.18 \\
\hline \multicolumn{4}{|l|}{ Highest qualification } \\
\hline - 10th grade or lower & $28(31.8 \%)$ & $7(28 \%)$ & 0.8 \\
\hline - 12th grade & $21(24 \%)$ & $6(24 \%)$ & 1.00 \\
\hline - Undergraduate & $26(29.5 \%)$ & $7(28 \%)$ & 1.00 \\
\hline - Postgraduate and above & $13(14.7 \%)$ & $5(25 \%)$ & 0.54 \\
\hline \multicolumn{4}{|l|}{ Marital status } \\
\hline - Married & $17(19.3 \%)$ & $5(20 \%)$ & 1.00 \\
\hline - Have children & $10(11.4 \%)$ & $3(12 \%)$ & 1.00 \\
\hline
\end{tabular}


Table 2 Physical and mental health concerns of survivors and siblings

\begin{tabular}{|c|c|c|c|}
\hline Health concerns & Survivors $(n=88)$ & Sibling $(n=25)$ & $p$ \\
\hline \multicolumn{4}{|l|}{ Pre-existing concerns } \\
\hline Pre-existing chronic illness & $19(21.6 \%)$ & - & \\
\hline On regular medication & $17(19 \%)$ & 1 (multivitamin) & \\
\hline Missed medication & 1 & - & \\
\hline Needed to visit hospital, but could not & $46(52.3 \%)$ & & \\
\hline \multicolumn{4}{|l|}{ New concerns (March 15-September 15, 2020) } \\
\hline Health issues in the past 6 months & $26(29.5 \%)$ & $12(48 \%)$ & 0.09 \\
\hline - Fever/bodyache/headache/sore throat/cough & $16(18 \%)$ & $10(40 \%)$ & $\mathbf{0 . 0 3}$ \\
\hline - Weight gain & $8(9 \%)$ & $2(8 \%)$ & 1.00 \\
\hline - Tiredness/lack of energy & $8(9 \%)$ & $1(4 \%)$ & 0.6 \\
\hline $\begin{array}{l}\text { - Lack of concentration/anxiety/depression/sleep } \\
\text { disturbance }\end{array}$ & $15(17 \%)$ & $4 *(16 \%)$ & 1.00 \\
\hline - Visited local general practitioner & $12(13.6 \%)$ & $5(20 \%)$ & 0.5 \\
\hline - Required medication & $8(9 \%)$ & $1(4 \%)$ & 0.6 \\
\hline - Hospitalized & $1(1.1 \%)$ & - & \\
\hline Satisfaction with health & $\begin{array}{l}\text { - Satisfied/very satisfied - } 61(69 \%) \\
\text { - Neutral - } 16(18 \%) \\
\text { - Dissatisfied - } 11\end{array}$ & $\begin{array}{l}\text { - Satisfied/very satisfied — } 19(76 \%) \\
\text { - Neutral - } 6(24 \%)\end{array}$ & 0.6 \\
\hline Satisfaction with access to health services & $\begin{array}{l}\text { - Satisfied/very satisfied - } 62(70.5 \%) \\
\text { - Dissatisfied - 6 (6.8\%) } \\
\text { - Neutral - } 20(22.7 \%)\end{array}$ & $\begin{array}{l}\text { - Satisfied/very satisfied - } 20(80 \%) \\
\text { - Dissatisfied - } 1(4 \%) \\
\text { - Neutral - 4 (16) }\end{array}$ & 0.8 \\
\hline Able to get enough exercise & $44(50 \%)$ & $11(44 \%)$ & 0.6 \\
\hline Able to maintain a healthy diet & $65(74 \%)$ & $19(77 \%)$ & 1.00 \\
\hline Tested COVID positive & 4 & 0 & \\
\hline Symptoms of COVID, tested negative & 2 & 1 & \\
\hline Satisfied with knowledge of COVID & $\begin{array}{l}\text { Yes }-73(83 \%) \\
\text { No or unsure }-15(17 \%)\end{array}$ & $\begin{array}{l}\text { Yes }-21(84 \%) \\
\text { No or unsure }-4(16 \%)\end{array}$ & 1.00 \\
\hline Able to take adequate precautions against COVID & $76(86.3 \%)$ & $18(72 \%)$ & 0.12 \\
\hline $\begin{array}{l}\text { Concerns about COVID infection, either as a cancer } \\
\text { survivor or with a survivor in the family }\end{array}$ & $\begin{array}{l}\text { - Yes }-32(36.3 \%) \\
\text { - No or unsure }-56(65.7 \%)\end{array}$ & $\begin{array}{l}\text { - Yes - } 10(40 \%) \\
\text { - No or unsure - } 15(60 \%)\end{array}$ & 0.8 \\
\hline
\end{tabular}

*1 sibling had self-reported clinical depression

A third of CCS (33\%) reported significant disruption of their social life during this period, a similar proportion (34\%) were neutral or dissatisfied about their living conditions and a fourth $(23 \%)$ of CCS felt that the COVID pandemic would change their life significantly in the future. Although $45 \%$ of employed siblings lost their jobs compared to $17 \%$ of employed CCS $(p=0.02)$, financial issues were comparable between CCS and siblings post-pandemic $(n=49,55.6 \%$ vs $n=11,44 \% p=0.3$ ). A comparable proportion of CCS and siblings reported a change in social life and felt that the COVID pandemic would affect their present and future lives. More CCS reported being able to cope with the stresses of the pandemic ( $n=84,95.4 \%$ vs $n=20,80 \%, p=0.06)$. While most CCS and siblings found that family/friends, old and new hobbies and prayer/meditation helped with their mental health, half (50\%) of siblings did not 'do anything special' to cope with their stress.

\section{Discussion}

This study is one of the few systematically reporting on the impact of the COVID pandemic on survivorship care and on adolescent and young adult survivors of childhood cancer, and the first one from India.

Services In the first wave of the pandemic in India, Mumbai - the location of our centre - was the worst hit city. Generally, the busiest time of the year at our clinic is mid-March to end-July, and December coinciding with school and university vacations across various parts of India, when survivors prefer to schedule their visits. In 2020, a nation-wide lockdown occurred during these months, and a large number of survivors could not attend their scheduled annual followup. Since hospital policy allowed risk-based assessment and 
Table 3 Psychosocial and family concerns in cancer survivors and siblings

\begin{tabular}{|c|c|c|c|}
\hline & Survivors $(n=88)$ & Sibling $(n=25)$ & \\
\hline \multicolumn{4}{|l|}{ Family concerns } \\
\hline Family member with COVID & $16(18 \%)$ & $4(16 \%)$ & \\
\hline Staying with family & $83(94 \%)$ & $25(100 \%)$ & \\
\hline Satisfaction with living circumstances & $\begin{array}{l}\text { - Satisfied/very satisfied - } 58(65.7 \%) \\
\text { - Dissatisfied - } 8(9 \%) \\
\text { - Neutral - } 22(25 \%)\end{array}$ & $\begin{array}{l}\text { - Satisfied/very satisfied - 20(80\%) } \\
\text { - Dissatisfied - } 1(4 \%) \\
\text { - Neutral - 5 (20\%) }\end{array}$ & 0.22 \\
\hline Personal relationships with family & $\begin{array}{l}\text { - Satisfied/very satisfied - } 72(81.6 \%) \\
\text { - Dissatisfied - } 4 \\
\text { - Neutral - } 12\end{array}$ & $\begin{array}{l}\text { - Satisfied/very satisfied - } 22(88 \%) \\
\text { - Dissatisfied - } 3\end{array}$ & 0.56 \\
\hline Chronic health issues in family & 20 & $2^{*}$ & \\
\hline \multicolumn{4}{|l|}{ Financial issues } \\
\hline Lost job (amongst employed) & $7 / 41(17 \%)$ & $10 / 22(45 \%)$ & 0.02 \\
\hline Worked from home & $21 / 41(51 \%)$ & $5(22.7 \%)$ & $\mathbf{0 . 0 3}$ \\
\hline Family members lost job & $28(32 \%)$ & $9(36 \%)$ & 0.8 \\
\hline Financial issues post-pandemic & $49(55.6 \%)$ & $11(44 \%)$ & 0.3 \\
\hline Medical/health insurance & $\begin{array}{l}\text { Yes }-15(17 \%) \\
\text { No or unsure }-73(83 \%)\end{array}$ & $\begin{array}{l}\text { Yes }-4(16 \%) \\
\text { No or unsure }-21(88 \%)\end{array}$ & 1.00 \\
\hline \multicolumn{4}{|l|}{ Psychosocial issues } \\
\hline Change in social life & $\begin{array}{l}\text { - Major change }-33(37.5 \%) \\
\text { - Slight or no change }-55(62.5 \%)\end{array}$ & $\begin{array}{l}\text { - Major change - } 10(40 \%) \\
\text { - Slight or no change - } 15(60 \%)\end{array}$ & 0.8 \\
\hline $\begin{array}{l}\text { Will the COVID pandemic affect you in } \\
\text { the future? }\end{array}$ & $\begin{array}{l}\text { - Very much - } 26(23.8 \%) \\
\text { - Slightly/unsure/no change - } 62(70 \%)\end{array}$ & $\begin{array}{l}\text { - Very much - } 9(32 \%) \\
\text { - Slightly/unsure/no change - } 16(64 \%)\end{array}$ & 0.6 \\
\hline $\begin{array}{l}\text { Do you think this pandemic might } \\
\text { improve your life in the future? }\end{array}$ & Will improve $-5(5.6 \%)$ & Will improve $-1(4 \%)$ & 1.00 \\
\hline $\begin{array}{l}\text { Were you able to cope with stress during } \\
\text { this period? }\end{array}$ & Able to cope $-84(95.4 \%)$ & Able to cope $-20(80 \%)$ & 0.06 \\
\hline How did you cope with stress? & $\begin{array}{l}\text { - Being with friends and family }-42 \\
(50 \%) \\
\text { - Old/new hobbies and interests - } 28 \\
(33 \%) \\
\text { - Prayer and meditation }-18(21.4 \%) \\
\text { - Nothing special - } 10(12 \%)\end{array}$ & $\begin{array}{l}\text { - Being with friends and family }-7(35 \%) \\
\text { - Old/new hobbies and interests }-5(20 \%) \\
\text { - Prayer and meditation }-3(12 \%) \\
\text { - Nothing special - } 10(50 \%)\end{array}$ & 0.002 \\
\hline Call requested & 41 & - & \\
\hline
\end{tabular}

*Excluded sibling with cancer

follow-up, survivors with active medical concerns continued to visit. With lifting of restrictions and acclimatization to the 'new-normal', most survivors who were able to travel preferred to come for in-person follow-up, leading to prepandemic number of clinic visits in the first half of 2021. This was especially so with survivors residing in Mumbai and surrounding areas, and those with medical/psychosocial concerns who depend on our in-house onco-endocrinology, cardio-oncology and hepatitis services, and receive complete financial support for this medical care. Due to financial and logistical reasons, many survivors with medical issues requiring treatment prefer to make the journey to our centre rather than get treated at their local centres. There has been a steady and sustained increase in the of tele survivorship, especially in survivors with no/few late effects, easy access to technology and residing in places distant from Mumbai. Our medical team has encouraged distant follow-up in this group of survivors. Therefore, the choice of modality (inperson vs distant) is often a combination of multiple factors. Interestingly, telephone continues to be the preferred mode of communication in our setting.

Impact of the pandemic on survivors Nearly all studies on survivors of cancers during the COVID pandemic have noted wide-ranging issues: changes in physical and emotional functioning, mental health issues, social isolation, worsening of quality of life and financial insecurity [20-22]. Studies of AYA patients and survivors of cancer during the pandemic have also consistently found increased levels of psychological distress and anxiety, often due to feelings of isolation and lack of support [23, 24]. However, a recent study in families of AYA brain tumour survivors has also reported positive changes including improved family cohesion [23]. 
The results of our survey found that while there was a high burden of health concerns amongst CCS, this was comparable with that of their siblings. Nearly half of siblings reported new health concerns compared to a third of CCS, although most of these did not require intervention.

Around $10 \%$ of both groups reported mental health issues in varying degrees. Although most CCS and siblings reported satisfaction with their personal health and access to health services, more CCS than siblings were dissatisfied with their personal health, mainly due to new-onset concerns as our data suggests. While only four (4.5\%) CCS in this cohort had COVID infection, it is likely that a far higher number have tested positive subsequently. The presentation of COVID was mild, as reported elsewhere [25].

Of great concern was the financial distress reported during this period in over half of CCS and siblings, with a significant proportion having lost their jobs (17\% of employed survivors and $45 \%$ of employed siblings). This probably reflects the nation-wide, and indeed global, socio-economic impact of the pandemic, which has led to job losses and fall in household incomes [26, 27].

Contrary to expectation, job loss was higher amongst employed siblings than CCS. This might be due to fact that more survivors had jobs that allowed them to work from home and ostensibly offered more job security, although there was a high proportion of 'part-time' jobs in both groups. Several CCS are preferentially employed by nonprofit organizations associated with our hospital, and have worked through the pandemic. In spite of lower job loss, more CCS reported financial issues post pandemic whether this is due to job loss amongst other family members or due to other reasons is not clear.

Both CCS and siblings experienced major, but comparable, changes in their social lives and anticipated that the pandemic would lead to sustained changes in their future. One of the most interesting findings of this survey was how both groups perceived and managed stress during this period. While most CCS coped with their stress, $20 \%$ of siblings were unable to do so. Given the relatively small sample size, the significance of this finding needs to be explored further. More survivors reported increased reliance on family and friends, and prayer/meditation, and efforts to overcome stress compared to half of siblings who did 'nothing special'. Post-traumatic growth and improved resilience are well recognized amongst survivors of childhood cancer [28]. While siblings of children with cancer also face adversity and disruptions as a consequence of cancer in the family, psychological parameters in adult siblings of adult survivors of childhood cancer are comparable to the normal population [29]. Additionally, the late effects Clinic at our centre and the associated support systems were easily accessible by telephone and email to most AYA survivors of childhood cancer at our centre [18]. We had proactively reached out to our survivors, whereby concerns of several of our survey respondents might have been addressed. Nearly half of CCS surveyed requested personal teleconsultations, highlighting the ongoing need of CCS for information and support.

Limitations of the study The surveys were not based on any validated questionnaires, but were designed keeping in need the issues faced by our survivor population. The survey was conducted in 88 survivors of cancer and 25 siblings, who were mostly educated, predominantly urban (based in Mumbai, the same city as our centre), with access to email/ WhatsApp and potentially better access to healthcare. The relatively small sample size (especially of siblings) and the possible selection bias are limitations of this study. Although administration of the survey via telephone would potentially have allowed us to enroll a larger sample size, we felt this would not be a practical approach. While comparison of survivor and sibling responses proved valuable, it is possible that the family-related responses had significant overlap.

Importantly, after this survey was conducted, there has been a second wave of COVID in India, which has affected far more of the population including several of our survivors; several survivors have been vaccinated and the impact of the second (and subsequent) wave on our survivors remains to be seen.

Nevertheless, the insights gained from the first year of the pandemic were of great practical value in the past few months, and will continue to inform our services in the future. The COVID pandemic has been unpredictable and is likely to be prolonged. Keeping this in mind, we continue to actively encourage distant follow-ups. Survivors with mental or physical health issues and those at high risk of psychosocial concerns are followed up frequently by physician and psychologist. The care of certain survivors with serious physical and mental health issues was and is coordinated with local health professionals in view of frequent travel restrictions. In the current scenario and possible future crisis situations, vulnerable populations like cancer survivors need multiple alternative sources of support including health professionals, family, peers and digital health. Effective and sustainable methods of physical, educational and vocational rehabilitation, financial and medical support need to be developed based on the collective experience of health professionals and support groups to achieve a 'new normal'. We believe that our understanding of the impact of the COVID pandemic on survivorship care and survivors would be of interest to all professionals involved in the care of childhood cancer survivors, especially as these can be extrapolated to similar scenarios in the future. 


\section{Conclusions}

The drastic fall in in-person follow-ups during the early months of the pandemic necessitated an increase in telesurvivorship, which still continues to be successful even after in-person follow-ups have normalized. Multiple modalities of communication may be effective depending on the survivors' access to technology. AYA survivors of childhood cancer experienced significant physical and mental health issues as well as social isolation and financial distress as a result of the COVID pandemic. In most part, these were comparable with siblings. Cancer survivors appear to have coped better than siblings during this stressful time, possibly as a result of multiple sources of support, including family, peer support groups and healthcare professionals. Development of a holistic support system for cancer survivors in stressful situations should be a focus of future interventional research.

Supplementary Information The online version contains supplementary material available at https://doi.org/10.1007/s00520-021-06788-4.

Acknowledgements We wish to acknowledge Shreyas Chunekar and Kiran Gowda, data managers at the ACT Clinic, Tata Memorial Hospital, Mumbai, for facilitating distant follow-ups during the past year.

Author contribution All authors have contributed in significant ways to the concept, preparation and review of the manuscript and have agreed to the final submitted version.

Data availability The data that support the findings of this study are available from the corresponding author upon reasonable request.

Code availability Not applicable.

\section{Declarations}

Ethics approval Approved by the Institutional Ethics Committee of Tata Memorial Hospital (details in text).

Consent to participate All participants in the survey have consented to participate.

Consent for publication Not applicable.

Conflict of interest The authors declare no competing interests.

\section{References}

1. Kuderer NM, Choueiri TK, Shah DP et al (2020) Clinical impact of COVID-19 on patients with cancer (CCC19): a cohort study. The Lancet 395(10241):1907-1918. d

2. Edge R, Mazariego C, Li Z et al (2021) Psychosocial impact of COVID-19 on cancer patients, survivors, and carers in Australia: a real-time assessment of cancer support services. Support Care Cancer 11:1-1
3. Islam JY, Vidot DC, Camacho-Rivera M (2021) Evaluating mental health-related symptoms among cancer survivors during the COVID-19 pandemic: an analysis of the COVID impact survey. JCO Oncology Practice 17(9):e1258-e1269

4. Parambil BC, Moulik NR, Dhamne C et al (2021) COVID-19 in children with cancer and continuation of cancer-directed therapy during the infection. Indian J Pediatr 11:1-7. https://doi.org/10. 1007/s12098-021-03894-3

5. Moreira DC, Millen GC, Sands S, Kearns PR, Hawkins DS (2021) The care of children with cancer during the COVID-19 pandemic. Am Soc Clin Oncol Educ Book 14(41):1

6. Richards M, Anderson M, Carter P, Ebert BL, Mossialos E (2020) The impact of the COVID-19 pandemic on cancer care. Nature Cancer 1(6):565-567

7. Riera R, Bagattini ÂM, Pacheco RL, Pachito DV, Roitberg F, Ilbawi A (2021) Delays and disruptions in cancer health care due to COVID-19 pandemic: systematic review. JCO Global Oncology 7(1):311-323

8. Ranganathan P, Sengar M, Chinnaswamy G et al (2021) Impact of COVID-19 on cancer care in India. Lancet Oncol S1470-2045(21):00240

9. Graetz D, Agulnik A, Ranadive R et al (2021) Global effect of the COVID-19 pandemic on paediatric cancer care: a cross-sectional study. The Lancet Child \& Adolescent Health 5(5):332-340

10. Vasquez L, Sampor C, Villanueva G et al (2020) Early impact of the COVID-19 pandemic on paediatric cancer care in Latin America. Lancet Oncol 21:753-755

11. Chan A, Ashbury F, Fitch MI, Koczwara B, Chan RJ, MASCC Survivorship Study Group (2020) Cancer survivorship care during COVID-19-perspectives and recommendations from the MASCC survivorship study group. Support Care Cancer 28:3485-8

12. Barnett M, McDonnell G, DeRosa A et al (2016) Psychosocial outcomes and interventions among cancer survivors diagnosed during adolescence and young adulthood (AYA): a systematic review. J Cancer Surviv 10(5):814-831

13 Kurkure PA, Panda SP, Prasad M, Goswami S (2016) Adolescent and young adult (AYA) survivors of childhood cancers: a challenge in after completion of therapy (ACT) clinic in resourceconstrained country. J Clin Oncol 34(3_suppl):19-19

14. Prasad M, Goswami S Barriers to long-term follow-up in adolescent and young adult survivors of childhood cancer: perspectives from a low-middle income setting. Journal: Pediatric Blood \& Cancer. https://doi.org/10.1002/pbc.29248

15. Košir U, Loades M, Wild J et al (2020) The impact of COVID19 on the cancer care of adolescents and young adults and their well-being: results from an online survey conducted in the early stages of the pandemic. Cancer 126(19):4414-4422

16. Forster VJ, Schulte F (2021) Unique needs of childhood cancer survivors during the COVID-19 pandemic. Support Care Cancer 29(1):17-19

17. Kurkure PA, Achrekar S, Uparkar U, Dalvi N, Goswami S (2003) Surviving childhood cancer: what next? Issues under consideration at the After Completion of Therapy (ACT) clinic in India. Med Pediatr Oncol 41(6):588-589

18. Arora RS, Arora PR, Seth R, Sharma S, Kumar C, Dhamankar V, Kurkure P, Prasad M (2020) Childhood cancer survivorship and late effects: the landscape in India in 2020. Pediatric Blood \& Cancer. 67(9):e28556

19. Dhamne C, Vora T, Prasad M et al (2020) Comment on: The COVID-19 pandemic: a rapid global response for children with cancer from SIOP, COG, SIOP-E, SIOP-PODC, IPSO, PROS, CCI, and St Jude Global. Pediatr Blood Cancer 67(9):e28462

20. Seven M, Bagcivan G, Pasalak SI, Oz G, Aydin Y, Selcukbiricik F (2021) Experiences of breast cancer survivors during the COVID19 pandemic: a qualitative study. Support Care Cancer 27:1-3 
21. Amaniera I, Bach C, Vachani C et al (2021) Psychosocial impact of the COVID-19 pandemic on cancer patients, survivors and caregivers. J Psychosoc Oncol 7:1-7

22. Gallo O, Bruno C, Locatello LG et al (2021) The impact of the COVID-19 pandemic on the quality of life of head and neck cancer survivors. Support Care Cancer 15:1-8

23. Fisher AP, Patronick J, Gerhardt CA, Radonovich K, Salloum R, Wade SL (2021) Impact of COVID-19 on adolescent and emerging adult brain tumor survivors and their parents. Pediatr Blood Cancer 68(9):e29116

24. Hanghøj S, Pappot N, Hjerming M, Taarnhøj GA, Boisen KA, Pappot H (2021) Experiences of social isolation during the COVID-19 lockdown among adolescents and young adult cancer patients and survivors. J Adolesc Young Adult Oncol 10(2):142-147

25. Jimenez-Kurlander L, Antal $\mathrm{Z}$ et al (2021) COVID-19 in pediatric survivors of childhood cancer and hematopoietic cell transplantation from a single center in New York City. Pediatr Blood Cancer 68(3): 28857

26. Azim Premji University (2021) State of working India 2021: one year of Covid-19. Centre for Sustainable Employment, Azim
Premji University. https://cse.azimpremjiuniversity.edu.in/stateof-working-india/swi-2021/. Accessed 20 Aug 2021

27. Goel I, Sharma S, Kashiramka S (2021) Effects of the COVID-19 pandemic in India: an analysis of policy and technological interventions. Health Policy Technol 10(1):151-164

28. Zebrack BJ, Stuber ML, Meeske KA et al (2012) Perceived positive impact of cancer among long-term survivors of childhood cancer: a report from the childhood cancer survivor study. Psychooncology 21(6):630-639

29. Buchbinder D, Casillas J, Krull KR et al (2011) Psychological outcomes of siblings of cancer survivors: a report from the Childhood Cancer Survivor Study. Psychooncology 20(12):1259-1268

Publisher's note Springer Nature remains neutral with regard to jurisdictional claims in published maps and institutional affiliations. 